\title{
Migrant Cuisine, Critical Regionalism and Gastropoetics
}

\section{BEN HIGHMORE}

UNIVERSITY OF SUSSEX

This essay is mainly based around two sentences from Nadeem Alslam's 2004 novel Maps for Lost Lovers. One sentence is long and rhapsodic, though with a nonrhapsodic sting in its tail; the other is short and humdrum, though highly aromatic. But before I write these sentences down for you, I want to quickly make a more general point concerning the practice of cultural studies. It concerns what aesthetics could mean for cultural studies, and what sorts of practices it could foster. That this has pertinence for the study of food culture is, I hope, borne out by what follows.

Graeme Turner's very engaging book What's Become of Cultural Studies? quite rightly (to my mind) criticises the practice of 'freestanding and evaluative textual analysis'. He worries that displays of interpretative energy, mobilised to condemn or condone a television series, for instance, without connecting it to the wider social realm threatens to turn cultural studies into a 'performative or perhaps even an aesthetic, rather than a political practice'. ${ }^{1}$ I know what he means by 'aesthetic' in this sense (he means a judgement of value in relation to a regime of taste), and I can imagine the sort of textual analyses he is scornful of. My worry, however (and it 
might be Turner's too), would be that without the sort of excessively concentrated consideration of the dense forms we call 'cultural' it is hard to get a full-ish sense of what the world feels like and how we might go about communicating it to each other. Clearly Turner is not advocating a retreat from such concerns, far from it, but in the desire for the political (and with it the judgement of 'public good' or 'useful knowledge') the slower work of description and sensorial engagement might simply seem too luxurious, too decadent. In encouraging a more descriptive form of cultural studies (one that might often seem luxurious and slow, that would always be social, but might not always end up with something useful and good) I want to resuscitate aesthetics not as a forum of evaluation but as a mode of sensorial description.

To this end it is always worth remembering that before aesthetics designated a judgement or rarefied experience, or was used to single out specific social activities (writing, picturing and the like) while ignoring others (hiking, cooking and so on), it was a name given to the vast terrain of sensorial life. ${ }^{2}$ Aesthetics pointed us towards aspects of life that couldn't be covered by reason. This was not the world without reasons; rather it was the world whose reasons couldn't be reasoned. The directing of aesthetics towards a concern only with the registration of the sensorial in works of art is a partial and fundamentally alienated fulfilment of the possibility of aesthetics. While art works often provide privileged access to the communication of sensorial life, the price for designating art as the primary or only arena for aesthetics is often the eradication of the worldliness of aesthetics. Seen in this way such a limited aesthetics just isn't worth the price of admission.

A socially oriented aesthetics, though, would recognise aesthetics as our creaturely and lively immersion in, and response to, the world: it would be an arena for accounting and recounting our sensate life, our sensorial orientations and our material contacts. In this context artworks (novels, paintings, films, cartoons and such like) could be seen as field reports and ethnographic data, grappling with registering sensorial life and the affects and effects that the orchestration of the world has on it. All ethnographic data deploys tropes, conventions, displacements and so on, and these formal aspects are a central character of their status as data. To claim that a novel (or a letter, or a response to an inquiry) provides access to cultural feelings is to claim realism for our ways of apprehending it: a realism that 
sees the real as made up of beliefs and matter, and sees experience as located in the figural and the physical.

By characterising our initial contacts with the world as aesthetic, aesthetics is both foundational and preliminary. It is neither the epiphenomena scaffolded onto something of more basic significance, nor the final word on our apprehension of, and agency in, the world. It is this dual status as a sort of provisional foundation that makes it such a significant arena for cultural studies' involvement. An artwork (in this case a novel) is not meant to serve as representative of a particular kind of experience. In the world of aesthetics it is the singularity of experience that counts, but singularity is not the refusal of the social; rather, it is the social refined yet unfinished. To move from the singular to the social doesn't require the generalisation of experience but the detailing of its specific grammar-its poeticsas the figural forms connect to an alimentary geography and a set of possible feelings. ${ }^{3}$

But what is it that we could want from an aesthetic ethnography of cultural feelings? I think Lauren Berlant has it right when she writes:

Aesthetics is not only the place where we rehabituate our sensorium by taking in new material and becoming more refined in relation to it. But it provides metrics for understanding how we pace and space our encounters with things, how we manage the too closeness of the world and also the desire to have an impact on it that has some relation to its impact on us. ${ }^{4}$

'Refined' in the sense that Berlant uses it is not about producing 'refined feelings' but of producing feelings that have in some sense been processed through their contact with the world: sharpened, blunted, sensitised, battered, and so on. But it is Berlant's focus on 'pace and space' in relation to the 'too closeness of the world' that motivates me and seems particularly relevant for writing about migrant food.

Here, then, I take up the project of 'critical regionalism' and 'gastropoetics' as a way of moving from the tightly figured frame of a fragment from a novel, to the histories, geographies, and affects that impact on it. Gastropoetics is the term that Parama Roy uses for her close readings of food-related texts. For her, a focus on the 'alimentary tracts of colonial and postcolonial India': 
Enables us most obviously to scrutinize forms of soul making and selffashioning that we have come to see as absolutely crucial to colonial transformation as situated simultaneously in theatres of the flesh and of the psyche, rather than the latter alone. Its absorption in banal and ephemeral practice sometimes provides a novel purchase on figures, texts, and events usually framed by less vulgar concerns. Perhaps most importantly, it insists that a scrutiny of a grammar of ingestion and avoidance involves an attentiveness to the complex moral structure of embodiment. 5

Roy's 'theatres of the flesh and of the psyche' are highly suggestive and generative for my essay, as is her attention to the way moral structures are embodied. Such work couples concerns with physicality and meaning to the dramaturgy of the ongoing-ness of life. The theatres of flesh and psyche might also be met by a whole range of other theatres that are fleshy and psychical but also economic, commercial, historical, domestic and so on, and which invoke a transregional geography that includes regions as small as kitchens and local shops and as large as transnational territories (of language and food traditions, for instance). In this essay gastropoetics is a form of aesthetic attention that allows these varied regions to be glimpsed in the entanglements of an ordinary act of cooking. If it does nothing else then aesthetics, as I invoke it, invites us to stay a little longer within the envelope of the unfolding of experience; to linger a while amid the materialities of life in process as it performs its connections and disconnections across spaces both fleshy and psychical.

\section{-MIGRANT CUISINE}

Maps for Lost Lovers is a complex narrative that takes place in an unnamed town in northern England. Its language and plotting are dense and avoid any easy narrative synopsis. To understand the sentences that follow it is enough to know that we are in the presence of a family of Pakistanis who are living in England in a place that they name Dasht-e-Tanhaii; the Wilderness of Solitude, the Desert of Loneliness. Kaukab, mother of three grown-up children, is perhaps the loneliest of all but takes solace in her faith (Islam). She is married to Shamas, whose beliefs are decidedly secular (he is a communist). The narrative moves backwards and forwards in time as it spirals round the disappearance of two lovers-Jugnu and Chanda-who lived 
next door to Kaukab and Shamas. Jugnu is Shamas' brother. It eventually becomes clear that Jugnu and Chanda have been killed in an 'honour' killing by Chanda's two brothers Jugnu and Chanda can't be married as, although Chanda has been abandoned by her husband, the requisite number of years that would be needed to absolve the marriage haven't passed). ${ }^{6}$

Food plays a significant role in the story both as a conduit to memory and loss and as a daily practice of routine sustenance and the reproduction of tradition and community. Here Kaukab is remembering when Jugnu returned to England after a period in the United States. ${ }^{7}$ For his return she 'prepared for him all the food he had been missing during his years away':

Bamboo tubes pickled to tartness in linseed oil, slimy edoes that glued the fingers together as you ate them, naan bread shaped like ballet slippers, poppy seeds that were coarser than sand grains but still managed to shift like a dune when the jar was tilted, dry pomegranate seeds to be patted onto potato cakes like stones in a brooch, edible petals of courgette flowers packed inside the buds like amber scarves in green rucksacks, chilli seeds that were volts of electricity, the peppers whose stalks were hooked like umbrella handles, butter to be diced into cubes reluctant to separate, peas attached to the inside of an undone pod in a row like puppies drinking from their mother's belly: she moved through the aisles of Chanda Food \& Convenience Store and chose his favourite foods. Coriander was abundant in the neighbour's garden and it was just a matter of leaning over the fence with a pair of sewing scissors. ${ }^{8}$

These two sentences are central to this essay. They are made up of metaphors and precise locations; imaginaries and itineraries; dreams and materialities. The majority of the first sentence is an effervescent description that ends with a final clause of unfussy banality. The short second sentence is again informational and unfussy. It strikes me that these two sentences offer an excellent selection of what the everydayness of life might often consist of: evocations and locations; daydreams and shopping.

The effervescence of description (its rhapsodic quality) is partly produced by the excessiveness of its descriptions: descriptions that have a metaphorical aspect aimed at registering visual equivalences, alongside descriptions of tactile and 
gustatory properties. Taken as a list of qualities the food items are gluey, tart, electric, sand-like and sticky; they look like semi-precious stones, ballet slippers, rucksacks with scarves hanging out, umbrella handles and puppies suckling. It is a sprawling set of associations whose sensual dimensions seem striking. The context for these sentences (Jugnu's return to the family) and the preparation of what Kaukab hopes, with the 'help of Allah', will allow her cooking to be proclaimed the 'eighth, ninth and tenth wonder of the world', anticipates a description of her ingredients that will summon the flavours of Punjab/Pakistan. The novel constantly flirts with the tropes of magic realism and there seem to be some obvious references to the work of Gabriel García Márquez (and the novel One Hundred Years of Solitude): for instance Jugnu is a lepidopterist whose glowing hands (from working with luminous paints in a factory in America) prove irresistible to moths and butterflies. Such references prepare the reader for descriptions both fantastical and exotic, yet the descriptions of these foodstuffs seem to offer a calculated refusal of orientalist exoticism. As metaphorical references they appear sentimental and surprisingly literal. As associations, these initial similes (the pepper stalks are like umbrella handles) can be read as metonyms that take us to a range of possible situations and locales: to rainy, umbrella days (of the monsoons of 'home'; of the constant drizzle of northern England); to rucksacked travel and tourism (of backpackers in the subcontinent; of pioneering immigrants to England); to forms of jewelled adornment (India as the jewel-in-the-crown of Empire), and so on.

One way of reading the first sentence then would be as a play of expectation and realisation, and as a set of references that seem to evoke both Pakistan (and we gather that the family is from the Punjab region of Pakistan) and northern England, albeit inadequately and vaguely. But if the references of most of the first sentence appear both exuberant and banal, the final clause is simply bland: here she is in the shopping aisle of a local shop. And the second sentence provides more of the same: the neighbour has lots of coriander and she reaches over to get some. I will need to come back to how all these elements work together, but for the moment it is worth following the locations mentioned here: a local Pakistani food shop; a neighbour's garden.

It is worth noting that the first migrants from the subcontinent (and the Caribbean and Africa) who came to Britain in the nineteenth and early twentieth 
centuries tended to settle in dockland areas of Britain. ${ }^{9}$ For instance, in Cardiff (Wales) migrants populated the small area near the docks called Butetown (also known as 'Tiger' bay). In 1950 the journalist A.L. (Bert) Lloyd could describe this area as a place where 'the Arab rubs shoulders with the Barbadian and a Yoruba man chi-ikes a Kru man on their way to a meeting of the Sons of Africa'.10 Lloyd is describing the Butetown of his time, but the history of the area as a vibrantly multiethnic enclave, hedged in by the sea and a strenuously racist colour-bar, takes us back to the late eighteenth century. At the time Lloyd was writing Butetown was made up of more than fifty different nationalities: nearly all the migrants had at one time worked on the ships, nearly all were male; they married and had children with local white Cardiff women. ${ }^{11}$

The postwar migration from Pakistan, India and what became Bangladesh was a marked contrast. While initial migration was predominantly male, by the late 1960s and early 1970s other family members (from the subcontinent) began to join the men and establish family housing that only rarely crossed religious and national lines. Indeed, the patterns of migration would often result in large networks of families from the same villages and towns in the subcontinent relocating to a specific cluster of streets in England.12 Instead of being centred around docklands this postwar migration moved inland to cities like Coventry, Leicester, Birmingham and Bradford as well as outer-metropolitan areas like Southall, near London's Heathrow airport. The work available in the textile mills of Lancashire and Yorkshire (the author of Maps for Lost Lovers moved from Pakistan to Huddersfield in West Yorkshire, close to Bradford, in 1980 at the age of thirteen), as well as work in automobile factories and metal-based industry in the Midlands, were the primary ingredients that established this geography of working-class migration. ${ }^{13}$

But if the initial migration congregated around industry, predominantly Pakistani communities quickly established an infrastructure of businesses, Mosques and cultural practices that allowed them to maintain aspects of traditional culture, in a new setting. Food, of course, was a significant part of this cultural production and reproduction. Faced with the lack of recognisable (and fresh) herbs, spices, pulses and so on, Pakistanis set about producing them, importing them and selling them. The journalist Jo Monroe interviewed a range of British-Asians for her book Star of India. A daughter of a first-generation Bengali immigrant remembers: 
We lived on the seventh floor of a council block and had a balcony about the size of a single bed. I swear, from that tiny piece of outside space my mum could feed us for weeks. She had hanging baskets of radishes instead of petunias, she had window boxes of coriander instead of daffodils and where other people would be quite happy with geraniums she planted aubergines and chillies! ${ }^{14}$

Such work producing forms of sustenance that reproduce tastes and textures of 'home' had material consequences that produced forms of connection and disconnection. On the one hand 'the [white] neighbours used to complain, saying it was making the neighbourhood smell bad or look untidy', on the other hand 'other Bengalis in the area wanted to know tips for making the most of the British weather'.15

Another interviewee was a Punjabi man who came to Yorkshire in 1974 (at roughly the time Kakub was preparing her meal, let us imagine). Like many migrants he had been a farmer in Pakistan, but had become a factory worker in England:

I used to travel to work on the bus and see these tiny little farms and wondered how anyone could make a business from a patch of land so small. Then a colleague told me that they were allotments and that people treated them like a back garden that was just a long way away from their house. Anyway I put my name down with the council and eventually they gave me my plot.

By the time he gave up his allotment in 1998 he estimated that 'a quarter of the plots at his allotment gardens were used by Asians'.16 These informal practices of growing vegetables, spices and herbs were constant and sustaining, circulating to family and friends but also to the South-Asian restaurant trade (mainly Bangladeshi). But if these pioneering efforts demonstrate gustatory ways of inhabiting an inhospitable and unfriendly place like England, the Pakistani pioneers of the retail trade evidence quite remarkable efforts in gustatory place making.

To let the following facts register you need to remember that South-Asians accounted for only about 4 per cent of the UK population by the end of the last century. The following is a quantification of the South-Asian presence in retailing in the 1990s: 
Their major impact was in retailing, where they owned over 50 per cent of the 'cash and carry' stores and over 55 per cent of the independent (nonsupermarket) retail trade. In this trade they were primarily concentrated in six areas: grocers, CTNs (confectionary, tobacco and newsagents), offlicences, pharmacists, sub-postmasters and forecourt operators. In fact, South Asians owned 30,000 out of the 46,000 CTN shops and 70 per cent of the 83,200 independently owned neighbourhood shops. ${ }^{17}$

The neighbourhood shop, when it isn't a 'chain' mini-supermarket (Tesco, Sainsbury, and so on) is nearly always a Pakistani shop, selling herbs, spices, rice, pulses and vegetables alongside newspaper, tobacco and alcohol.18 If the ubiquitous Indian restaurant in the United Kingdom has traditionally been Bangladeshi, the corner shop has been Pakistani. ${ }^{19}$

Such enterprise in place making has mixed entrepreneurial skills with sustained self-exploitation. The local retail trade by the 1970s was a failing area of commerce, constantly undermined by the growth of large 'out-of-town' mega stores. While Asians managed to stop local streets in Britain from being entirely bereft of food stores, the price they paid was a phenomenal low pay and long hours, coupled with fairly persistent racism. ${ }^{20}$ Some British-Asians entrepreneurs achieved remarkable success in food retail but this was often as importers and producers (for example Patak pickles and Tilda rice as well as importers such as Sutewella who had been bringing 'rices, pulses, cereals, spices, herbs, pickles, edible oils and poppadoms' to the United Kingdom since 1957). ${ }^{21}$

Kaukab's move from her evocative list of ingredients to a precise location in 'Chanda Food \& Convenience Store' and her neighbour's coriander plants, connects us to material histories of gustatory place making, and through the store to networks of production and import that take us back to India and Pakistan. We can follow the ingredients, by imagining aspects that Kaukab doesn't notice: the can that the bamboo tubes are in; the packets of pomegranate seeds; the locally grown courgette flowers; and so on. We can see something of how she is materially connected (and disconnected), in her food making, to a variety of places. But how these places condense and displace each other, how they form imaginary and material presences, requires a slight detour. That detour is named 'critical regionalism'. 
-CRITICAL REgIONALISM

'Critical Regionalism' was first coined, as a term, within architectural theory as a challenge to forms of international modernism that prioritised rationalism while ignoring the demands of place.22 It has since migrated into other fields including postcolonialism and a loosely defined form of 'area-studies'. ${ }^{23}$ For some writers it has been used to designate a genre of cultural production (in dialogue with the way that the term 'regionalism' had previously been used), while for others it has had a more open significance in its challenge to the idea of the national and the global. It is in this latter spirit that I use it here, as a challenge to think about the overlapping forms of territory that are articulated and inhabited by cultural practices like cooking and eating.

It is, however, worth acknowledging the contribution made by architectural theory to these debates. Kenneth Frampton wrote in the early 1980s that:

Critical Regionalism tends to flourish in those cultural interstices which in one way or another are able to escape the optimising thrust of universal civilisation. Its appearance suggests that the received notion of the dominant cultural centre surrounded by dependent, dominated satellites is ultimately an inadequate model by which to assess the present state of modern architecture. ${ }^{24}$

Here he clearly has in mind a form of architecture that has emerged since the late 1950s in the wake of criticisms that universalising aspects of modernism seem bent on concocting an international language of modern architecture as well as general solutions to the world's urban problems. For architects like Alison and Peter Smithson (who might be seen as part of a generation of instigators of a critical regionalist sensibility in architecture) the 'Four Functions' prioritised by Le Corbusier (living, working, recreation and circulation) produced a net that allowed much of what was crucial to everyday life to fall through. They proposed a much more material concern with the spaces of life, and with the forms of identity and identification that animated them. Thus they were concerned with 'backyards', 'doorsteps', the sociality of 'streets', but also the larger forms of conurbation such as districts and cities. Underwriting their project was a concern with forms of living among others, where that living included 'involuntary associations' (say the people 
you have living in your street) as well as 'voluntary associations' (say those you identify with because they share your beliefs). ${ }^{25}$

What the Smithsons didn't pay much attention to were the forms of transregionalism that might cross national borders. ${ }^{26}$ To follow this in the context of Pakistani migration might mean reversing some of the Smithsons' accounts of association: here voluntary association might refer to the people in your street, while the involuntary associations would include the larger region of city and country. Yet for those within cultural studies, Kenneth Frampton's words must surely echo with debates about centres and margins, cores and peripheries that were brought into the foreground in the late 1980s in the name of Black Cultural Studies or postcolonial critical geography. ${ }^{27}$ It is partly by seeing critical regionalism through the concerns of postcolonialism and cultural geography that makes it a phrase that is so capable of resonating across various different fields of inquiry. For the study of food culture, critical regionalism might be most useful, not because it echoes with the desire of those that would promote 'regional produce' but precisely because it calls into question the very notion of region itself. The 'critical' part of critical regionalism is aimed perhaps first and foremost at the term 'region'.

Throughout this essay so far I have shifted uneasily with a variety of place names that often overlap. Do I mean England when I say Britain? What exactly is the United Kingdom? How can I talk about Bangladesh in relation to a restaurant culture that is clearly in existence in England in the 1920s (and before that too) when Bangladesh was un-thought, and the idea of Pakistan only an idea? If critical regionalism has work to do then surely this is one place to start. Politically, for instance, and in recognition that people in countries within the United Kingdom are struggling for control over their lives, I might want to use the term England or Wales rather than Britain. But how does this work with a history of migration that has systematically self-identified with Britain? In the hyphenated world of identity there are British-Pakistanis, British-Muslims, but there might be very few EnglishPakistanis or Scottish-Muslims (though plenty of Pakistanis who live in England and Muslims who live in Scotland). ${ }^{28}$

Critical regionalism doesn't come up with solutions to these problems but it might allow us to highlight them. There is no history of a nation without trauma, but the traumas of sub-continental nations are extensive. The partition of 1947, which 
created the Dominion of Pakistan (later the Islamic Republic of Pakistan) and the Union of India (later the Republic of India), divided centuries old regions that had been based on shared languages and food customs (as well as on forms of control). This partition put the demographics of religion in front of language and other cultural practices. The Punjab and Bengal were split by nation states born out of the dying embers of empire. Religion isn't just belief; it is foundational for nationhood. We need to be uneasy with our nouns, with our place names and our language. Perhaps critical regionalism could teach us to be systematically unsystematic in our naming: Pakistan-Punjab-India; Islam-Bengal-Hindu.

When I was about eight or nine we used to practice a naive existential form of place naming. It consisted of trying to make your address as long as possible. For instance, if you lived in an area of London you could write: 5 Park Square, Stepney, Tower Hamlets, East London, London, South-East England, England, British Isles, United Kingdom, Europe, the World, the Solar System. Each name seemed to propel you further and further away from any meaningful solidarity with your concrete existence, though every now and again something further away from your house would pull at you and exert its presence (World Cups and Olympic Games). For an existentially minded first-generation Sylheti living in Stepney in the 1970s would such elongation be possible or would it start to bifurcate somewhere in the middle? Place 'The Commonwealth' on this list and things start to bubble and come undone. You could create a fork in the list, something that would double back on itself and start to unfold. From 'the Commonwealth' you could move back to Bangladesh (or should that be Bengal?) and on further (or is that nearer?). And where on such an imagined geography would you put Islam or Christendom? Or rice or bread or potatoes?

Writing about the settlement patterns of South Asians in the Midlands in the 1960s and 1970s, Sinder Thandi writes:

Many of these settlers came from rural areas of South Asia-Punjabis, predominantly Sikhs (with a smaller number of Hindus), from the central districts of East Punjab (known as doaba), Muslims from Campbellpur in West Punjab, Kashmiri Muslims from Mirpur district, Muslims from Sylhet, a north-eastern district of Bangladesh. ${ }^{29}$ 
Nation states don't tell half the story, nor do religions, or languages: life doesn't follow that kind of geometry. In Maps for Lost Lovers place names connect and disconnect and remain mobile: 'As in Lahore, a road in this town is named after Goethe. There is a Park Street here as in Calcutta, a Malabar hill as in Bombay, and a Naag Tolla Hill as in Dhaka.'30 They name this cold northern town Dasht-e-Tanhaii; the Wilderness of Solitude.

My two sentences from Maps for Lost Lovers signal micro regions: a garden, a shop, a kitchen. Within these regions (and outside them too) are worlds of regions interlacing, conflicting, connecting: a palimpsest of religious regions and language regions; of family regions and food regions; of actual regions and imagined ones. These are the geographies of daily life and the theatres of flesh and psyche mapped as a complex poetics. The bamboo shoots may or may not be from Pakistan, but they bring something of that to this corner shop that bears the name of the soon to be dead lover. The pomegranate seeds may or may not be Punjabi but they bring that to the table too: they speak. The language of critical regionalism is unsteady and unsure but it is-if nothing else-intricate and textured in its poetics.

\section{-GASTROPOETICS}

I have pulled apart two sentences from a novel and now it is probably time to put them back together. They have constituted the evidence for my evidence (so to say): a set of evocations and references-material and fantastic. But no novel is just a set of references. Lauren Berlant invites us to consider aesthetics as concerned with the space and pace of our insertion in the world and the poetics of a novel can help us with this. Taken together these sentences figure a bathetic drive that the scene as a whole will fulfil. The euphoric descriptions of the ingredients culminate in the shopping aisle of a local shop. The figural insistence is of bathos: from the sublime ingredients, with all their associative suggestions, the character Kaukab is brought down to earth in a grocery store. The figure of bathos has an existential dimension of course, reminding us of our insertion in theatres of the flesh: the lower body is often the place for the bathetic, and food (as well as shops) will do for this.

It is tempting to see the bathos of these sentences as a figural emphasis on disappointment, and disappointment is the fundamental mood of much migration literature that takes England as its subject. Bathos is dynamically figured in the first 
sentence as the cadences of description come to an abrupt standstill in the food aisle of a grocery store. But this evens out in the following sentence as we are placed in the convivial act of cutting herbs from a neighbouring garden. But things are never quite as they seem. The food aisle of a shop might well seem to be a location primed for modern alienation, but this shop has a name (Chanda) and we find out that it is as much a community centre as a shop, and that for the local Pakistanis living in the small network of streets it is essential to their sense of place. Bathos is merely figured, not give. But the dinner that Kaukab is preparing does end up as a bathetic event. This meal that was to be the 'eighth, ninth, and tenth wonder of the world' becomes a terrible ordeal for Kaukab. Jugnu, the longed for brother-in-law, arrives with an unnamed white woman and a bottle of wine; a power cut plunges them into darkness; the two brothers (Jugnu and Shamas) blaspheme in Punjabi.

By candlelight the gathering begin to eat the delicious meal, while Kaukab is busy in the kitchen and refuses the invitations to sit and join the others. Throughout the meal Kaukab becomes more and more agitated. The initial dream of the meal fantasised in the local shop is coming apart. The meal that was prepared to repair the family in the name of Allah, in the name of Pakistan, slowly untangles for Kaukab as aversive elements are introduced as forms of contamination: the white woman, the wine, the blasphemy. The two brothers consider the foundations of Islam and prefer the endeavours of science: 'I trust what science says about the universe because I can see the results of scientific method all around me', says Jugnu in Punjabi. What Kaukab sees is the failure of science: 'Praising things like electricity: the very thing that's failed this evening, she had fumed inwardly, making you all sit in the darkness!' The electricity that arrives through the national grid can't be trusted: Allah and chillies (with their electric charge) can. As the scene progresses Kaukab is overcome with the deep obscenity of everything around her (the drink, the talk, the lewdness of the white woman's presence) so that the meal itself becomes infected with disappointment. In the candlelight gloom she serves her final course:

Kaukab had arranged four shoes on a tray and was pouring dahl into them as though they were plates.

Shamas was unable to stop her as she slipped from his repulsive wine-contaminated grasp and carried the tray into the pink room and 
placed it on the table before Jugnu and this white woman with a loud bang-dharma!

But if bathos is a figure of disappointment it is also a figure of ordinary, if precarious, continuity. It is the keeping-on of our keeping-on-going. The ordinary practices of place making and sustenance, that don't eradicate imaginary and mnemonic geographies, are the foundations of food culture. These aren't heroic flights of fancy; but nor do they eradicate such fancy either. These are the un-heroic acts of maintenance of a tradition that has to be minted anew in a foreign land that has been bequeathed through generations of trauma. These aren't the entrepreneurial 'flagships' but the continuous opening of a shop day in day out: the care and maintenance of window boxes and allotments.

Writing about South Asian gastropoetics (and gastropolitics), Parma Roy suggests that we pay attention to 'contingency, encounter, translation, contestation, and amalgamation'. ${ }^{31}$ These are I think the social forms that are figured in exceedingly condensed forms in the sentences in Maps for Lost Lovers. Such condensed and poetic utterances aren't the only places to go to find them: you can get them from anthropological and sociological studies too. ${ }^{32}$ The benefit of such figural and condensed language is you get a sense of it 'all at once' so to say: the hope and disappointment; the palimpsests of overlapping regions uncoiling and recoiling in kitchens and gardens. I warned you at the start that aesthetic attention might not provide 'really useful knowledge', might not be able to directly inform policy decisions, or help shape political actions: it merely lets us stay longer in the mix and multitude of life. But that 'merely' seems like a lot to me.

Ben Highmore is professor of Cultural Studies at the University of Sussex. His most recent books are A Passion for Cultural Studies (2009), Ordinary Lives: Studies in the Everyday (2011) and the edited collection The Design Culture Reader (2009). He is currently developing a project on cultural moods. 


\section{-NOTES}

${ }^{1}$ Graeme Turner, What's Become of Cultural Studies? Sage, London, 2012, p. 173-4.

${ }^{2}$ Admittedly as soon as it was named as such it became the subject of moralising projects to discriminate against the 'low' senses and promote the 'high' ones. Aesthetics and the possibilities of a social aesthetic approach to cultural studies is the subject of my book Ordinary Lives: Studies in the Everyday, Routledge, Abingdon, 2011, where a much fuller examination of these themes can be found. 3 For this essay I'm using the term 'alimentary geography' and its cognates to allude to materialistspatial-aesthetic accounts of 'food on the move' rather than to the specific academic field of geography. My approach is clearly indebted to the approach of cultural geography and cultural studies, particularly in such work as Elspeth Probyn, Carnal Appetites: FoodSexIdentities, Routledge, London and New York, 2000; David Bell and Gill Valentine, Consuming Geographies: We are Where we Eat, Routledge, London and New York, 1997; Lisa Heldke, Exotic Appetites: Ruminations of a Food Adventurer, New York and London, Routledge, 2003; and Uma Narayan, 'Eating Cultures: Incorporation, Identity and Indian Food', Social Identities, vol. 1, no. 1, 1995, pp. 63-86. Implicitly my approach is also engaged with the work of recent geographers who take their inspiration from the thingly-empiricism of people such as Bruno Latour and Jane Bennett: see for example the work of Ian Cook et al, 'Follow the Thing: Papaya', Antipode, vol. 36, no. 4, 2004, pp. 642-64 and 'Geographies of Food: Following', Progress in Human Geography, vol. 30, no. 5, 2006, pp. 655-66. The special issue of New Formations ('Food on the Move', no. 74, 2011) that I recently edited combines cultural geographical and cultural studies approaches to pursue the material, sensorial and spatial aspects of food as a crucial aspect of migrantculture and multiculture.

${ }^{4}$ Lauren Berlant, Cruel Optimism, Duke University Press, Durham, 2011, p. 12.

5 Parama Roy, Alimentary Tracts: Appetites, Aversions, and the Postcolonial, Duke University Press, Durham, 2010, p. 29. See also Parama Roy, 'Reading Communities and Culinary Communities: The Gastropoetics of the South Asian Diaspora', positions, vol. 10, no. 2, 2002, pp. 471-502. For an associated approach to gastropoetics see Anita Mannur, Culinary Fictions: Food in South Asian Diasporic Culture, Temple University Press, Philadelphia, 2010.

6 The topic of honour killings, while central to the story, is not my immediate concern here. For a nuanced and sensitive essay reviewing some of the recent literature around honour killings, which situates Maps for Lost Lovers as a way of complicating the representation of such acts, see Jacqueline Rose 'A Piece of White Silk', London Review of Books, vol. 31, no. 21, 5 November 2009, pp. 5-8. For a reading of the novel that situates it within the challenge of writing about migrant Muslim communities in the wake of 11 September 2001 see Lindsey Moore, 'British Muslim Identities and Spectres of Terror in Nadeem Aslam's Maps for Lost Lovers', Postcolonial Text, vol. 5, no. 2, 2009, pp. 1-19.

7 We are not given precise dates but we know that we are the 1970s and because there is a power cut later in the scene we can make a guess at this being late 1973 or early 1974 . This is the first time the 
phrase 'winter of discontent' is used in response to various strikes, a three-day week, and the rationing of electricity and isn't to be confused with the strikes of the winter of 1978-79 which didn't see largescale power cuts, but which did herald the arrival of Margaret Thatcher. See Andy Beckett, When the Lights Went Out: What Really Happened to Britain in the Seventies, Faber and Faber, London, 2009. 8 Nadeem Aslam, Maps for Lost Lovers, Faber and Faber, London, 2005, pp. 31-2.

${ }^{9}$ See for instance Rozina Visram, Asians in Britain: 400 years of History, Pluto, London, 2002. On the migrations to Britain of Bangladeshis from the Sylhet region see Yousuf Choundhury, The Roots and Tales of the Bangladeshi Settlers, Sylheti Social History Group, Birmingham, 1993.

10 A.L. Lloyd, 'Down the Bay', Picture Post, 22 April 1950, p. 15.

11 See Glenn Jordan's Down the Bay: Picture Post, Humanist Photography and Images of 1950s Cardiff, Butetown History and Arts Centre, Cardiff, 2001. This pattern was repeated in docklands in London and Liverpool, for instance. For a beautiful elaboration of this heritage see the film A Touch of the Tar Brush (1991) by John Akomfrah, which follows J.B. Priestley's 1934 English Journey to Liverpool to meet the descendants of these migrations.

12 Particularly useful for this section has been Michael H. Fisher, Shompa Lahiri and Shinder Thandi, $A$ South-Asian History of Britain: Four Centuries of Peoples from the Indian Sub-Continent, Greenwood World Publishing, Oxford, 2007, and Badr Dahya, 'Pakistanis in Britain: Transients or Settlers?', Race and Class, no. 14, 1973, pp. 241-77. This latter essay is an extensive participant observation from the 1960s into the 1970s, and so coincides with the historical moment being relayed in Maps for Lost Lovers.

13 Obviously the more middle-class migration of doctors, for instance, was more piecemeal and scattered.

14 Jo Monroe, Star of India: The Spicy Adventures of Curry, Wiley, Chichester, 2005, p. 169.

15 Ibid., p. 169.

16 Ibid., p. 169-70.

17 Fisher, Lahiri, and Thandi, p. 189.

18 The Asian 'open-all-hours' corner shop was as much a presence in the 1970s as in recent years. In fact, given the colonising impact of the big supermarkets in the development of 'local' mini-markets and the subsequent closing down of many Asian shops as a result, it is likely that its presence was even more significant (but probably not as dispersed).

${ }^{19}$ For an account of the Indian restaurant in the United Kingdom see my 'The Taj Mahal in the High Street: The Indian Restaurant as Diasporic Popular Culture in Britain', Food, Culture and Society, vol. 12, no. 2, 2009, pp. 173-90.

20 Trevor Jones, 'Small Business Development and the Asian Community in Britain', Journal of Ethnic and Migration Studies, vol. 9, no. 3, 1981, pp. 467-77.

21 Panikos Panayi, Spicing Up Britain: The Multicultural History of British Food, Reaktion, London, 2008, pp. $144-5$. 
22 The significant writings here are Kenneth Frampton's 'Critical Regionalism: Modern Architecture and Cultural Identity', in his Modern Architecture: A Critical History, Thames and Hudson, London, 1985, pp. 313-27, and Liane Lefaivre and Alexander Tzonis, Critical Regionalism: Architecture and Identity in a Globalised World, Prestel, New York, 2003.

${ }^{23}$ See for instance Gayatri Chakravorty Spivak, 'Nationalism and the Imagination', Lectora, no. 15, 2009, pp. 75-98; Judith Butler and Gayatri Chakravorty Spivak, Who Sings the Nation-State?: Language, Politics, Belonging, University of Chicago Press, Chicago, 2007; Cheryl Temple Herr, Critical Regionalism and Cultural Studies: From Ireland to the American Midwest, University Press of Florida, Gainesville, 1996; and Douglas Reichert Powell, Critical Regionalism: Connecting Politics and Culture in the American Landscape, University of North Carolina Press, 2007.

24 Frampton, p. 327.

25 See Alison and Peter Smithson, The Charged Void: Urbanism (edited by Chuihua Judy Chung), Monacelli Press, New York, 2005.

${ }^{26}$ Although Nehru was pictured in a 1950s collage occupying a flat in the East End of London, and when the Smithsons' 'street decks' complex was finally opened in 1971 it was occupied largely by Bangladeshis.

27 See for instance Isaac Julien and Kobena Mercer, 'De Margin and De Centre’ (originally published in Screen in 1988), in Stuart Hall: Critical Dialogues in Cultural Studies, ed. David Morley and Kuan-Hsing Chen, Routledge, London, 1996, pp. 450-64.

28 'Most non-whites identified themselves as British rather than English, Scottish or Welsh, and South Asians were no exception, identifying themselves with a strong British national identity-80 per cent of Pakistanis and Bangladeshis and 75 per cent of Indians identified themselves in this way', Fisher, Lahiri, and Thandi, p. 185.

${ }^{29}$ Fisher, Lahiri, and Thandi, p. 163.

30 Aslam, p. 28.

31 Roy, p. 20.

32 See for instance Krishnendu Ray, The Migrant's Table: Meals and Memories in Bengali-American Households, Temple University Press, Philadelphia, 2004, or David E. Sutton, Remembrance of Repasts: An Anthropology of Food and Memory, Berg, Oxford, 2001. 